\title{
Sarcastic Expressions and the Influence of Social Distance and Relative Power in The TV Series Friends
}

\author{
Shaula Noorhayu Shelldyriani, Aris Munandar* \\ English Department, Universitas Gadjah Mada, Indonesia \\ *Corresponding Author: arismunandar@ugm.ac.id
}

\begin{abstract}
This research aims to identify and classify the sarcastic expressions found in the TV Series Friends. It applies the theory proposed by Camp (2011) which categorized sarcasm into four classes: Propositional, Lexical, Like-Prefixed, and Illocutionary Sarcasm. Considering sarcasm as a Face Threatening Act (FTA), it also analyzes the influence of relative power and social distance to see how these two social variables influence the delivery of sarcastic expressions. The findings show that Illocutionary Sarcasm is the most frequently used class of sarcasm with 30 utterances (45\%) followed by Propositional Sarcasm which consists of 25 utterances (37\%), Lexical Sarcasm with 10 utterances (15\%) and lastly Like-Prefixed Sarcasm that have 2 utterances (3\%). With Illocutionary and Propositional Sarcasm are known to be the most straightforward class of sarcasm, the results also show that these two classes of sarcasm are mainly used when the social distance (D) is negative where the interlocutors does not have the obligation to be polite due to their close intimacy. In cases where the social distance has positive value, the value of power $(\mathrm{P})$ helps to determine which class of sarcasm is used. Furthermore, a clear context and common ground is essential to help identify sarcastic expressions and the intention underlying it.
\end{abstract}

Keywords: sarcasm, sarcastic expressions, social distance, relative power.

\section{INTRODUCTION}

Sarcasm, an aspect of communication in our daily lives and an element in figurative language, is defined as an utterance that means the opposite of the actual meaning. To understand sarcastic expressions, hearer must infer at another level of comprehension as it does not have a clear and distinct meaning (Caucci and Kreuz, 2012). Therefore, both the speaker and hearer must possess common ground of knowledge. Common ground is their mutual knowledge, beliefs and suppositions (Clark, 1996). Sarcasm is often associated with the intention to hurt or criticize the hearer's feelings such as defined by Liberman as "a cutting, often ironic remark intended to wound" (2004, p.1). However, sarcasm itself can be expressed in a humorous way and used positively.

American TV Series "Friends" which is known for its humor and the usage of sarcasm is the data source for this research. This TV Series focuses on the lives of a group of friends which have various life backgrounds, such as their careers, which could affect the delivery of sarcasm. There are many different factors that affect the delivery of sarcasm. These factors could be exaggeration of the sarcastic 
expressions, nature of the speaker, relationship of the speaker to the hearer, severity of the sarcasm and whether it was made in public or private (Toplak, 2000). Sarcasm is considered as an element in impoliteness so, power is one of the essential factor that correlates with it. Culpeper (1996) links both power and impoliteness by stating that impoliteness likely to occur when the speaker holds a higher power than the hearer. With this context, the research aims to also investigate the influence of the social variables towards the delivery of sarcasm.

\section{LITERATURE REVIEW}

A number of research on sarcasm have been conducted previously. Camp (2011) analyzes sarcasm by meaning inversion or by the opposite meaning of what the speaker said. He defines meaning more broadly by including illocutionary force and evaluative attitudes as well as formulates sarcasm into four classes; Propositional, Lexical, Like-prefixed and Illocutionary Sarcasm. Camp's theory is applied by Prabowo (2013) in identifying and classifying the expressions of sarcasm by combining Leech's theory (1983) to analyze their functions. Wulandari (2017) studies the interlocutors' backgrounds such as their origin. She reveals that interlocutors' background affect the delivery of sarcastic expressions. Bachtiar (2018) highlights the importance of common ground in order to understand sarcastic expressions. Similar to Prabowo and Wulandari, he also analyzes the functions of the sarcastic expressions.

Relevant with this article, Sandy (2012) focuses on the politeness theory and politeness strategies, specifically the usage of sarcasm in communication and American sitcom. This also relates to the notion of 'face' and how face work is managed in interaction. The findings show that the characters in American sitcoms who use sarcasm in conversation, often have hidden meanings in their utterance. He concludes that sarcasm uttered by the characters in American sitcoms has negative connotations but provides entertainment for the viewers.

This article focuses on the sarcastic utterances classified using Elisabeth Camp's theory. It classifies the sarcastic utterances into four classes, which are
Propositional Sarcasm, Lexical Sarcasm, Likeprefixed Sarcasm and Illocutionary Sarcasm. It discusses the influence of relative power and social distance on the sarcastic expressions.

\section{THEORETICAL FRAMEWORK}

\section{Speech Acts}

Speech acts is essential in the study of pragmatics to help to comprehend about an utterance. Speech acts is defined as an utterance that consists of a function in communication. For example, it is carried out when we are making an offer, apologizing, requesting, and so on. Yule (1996) divides speech acts into three levels, which are locutionary act, illocutionary force and perlocotionary act. The dialogue below is an example:

(1) S01E03 | 00:20:39,905 $\rightarrow$ 00:20:43,908 | PS \#6 |
Combination E \#10

Context: Everyone was upset that Monica and Alan had broken up.

Monica: I'm sorry...

Chandler: Oh, she's sorry! I feel better!

The first level of speech acts, locutionary act, is analyzed from the words itself: "I'm sorry" and "Oh, she's sorry! I feel better!" The second level, illocutionary force, is employed to form an utterance with a function. In this dialogue, Monica is making and apology and Chandler is making a statement. The last level, perlocutionary act, means the effect of the spoken utterance. Monica is apologizing to her friends because she broke up with Alan whom everyone else likes. In response to this, Chandler pretends that she does not hurt his feelings. The utterance he produces is sarcastic and is the effect of Monica's apology.

Yule (1996) explains two types of seech act which are direct and indirect speech. Direct speech act is used when the speaker communicates with the literal meaning of the utterance expressed, which means that there is a direct relationship between the form and the function of the utterance. Meanwhile, indirect speech act is to communicate 
with a different meaning of the utterance and the form and function does not have any relation. The utterances below of a mother telling her son to study are for illustration.

(2a) Go and study!

(2b) Don't you think you have to study?

(2c) You are failing.

(2d) At this rate, I think you are able to get into Harvard.

These untterances accomplish the same functions, which is to command the son to start studying. However, only (1a) is a direct speech act as the mother's intentionof giving a command is explicit. (4b), on the other hand, is an indirect speech act as it is in the form of an interrogative sentence. Similarly, (4c) and (4d) are indirect speech act spoken in a different way. In $(4 \mathrm{~d})$, the mother is speaking sarcastically by using verbal aggression to express a sense of evaluation towards her son.

Based on the explanation above, sarcasm belongs to an indirect speech act as it tends to have a different meaning from the stated words. McDonald (1999) explains that "sarcasm is an indirect form of speech in which its social function is to heighten the dramatic effect on the listener". Consequently, if the interlocutors fail to infer the intention underlying the utterance the speaker produces, misunderstanding will occur.

\section{Context}

Defined by Merriam-Webster, context is "the parts of a discourse that surround a word or passage and can throw light on its meaning". Yule (1996) asserts that pragmatics requires the interpretation of the meaning in a specific context and how context influences what is uttered. Peccei (1999) states that context is analyzed by the meaning of the word which is affected by several factors such as physical, social, socio-psychological, time and place are . Hence, context is a crucial aspect in sarcasm to determine the actual meaning of what is being said in a broader terms.

Cutting (2002) classifies context into three categories. First is the situational context which focuses on the physical environment where the conversation occurred. Second is the background knowledge context which is further categorized into two; cultural and interpersonal. Cultural knowledge refers to the ideas of life and interpersonal refers to the knowledge that the speaker possess about the hearer. Lastly, co-textual context or mainly known as co-text, it refers to the understanding of the conversation. Co-textual context deals with the linguistic element where it focuses on several concepts such as grammatical cohesion which include endophoric reference, substitution and ellipsis as well as lexical cohesion which consist of repetition, synonyms, superordinates and general words.

\section{Sarcasm}

There are several arguments regarding the definition of Sarcasm. The traditional definition of meaning inversion employs the view of semantics whereas the expressivists argues that sarcasm does not have any relations with meaning and instead it is "an expression of a dissociative attitude toward an evoked thought or perspective" Camp (2011). Camp believes that sarcasm is meaning inversion and in addition, the term "meaning" should be analyzed more broadly by including the illocutionary force and evaluative attitudes. He categorizes sarcasm into four classes, which are:

\section{Propositional Sarcasm}

The first type of sarcasm functions mostly like the traditional model of sarcasm, i.e., carrying the opposite meaning. In this category, sarcasm targets a particular proposition contrary to what would have been expressed by a sincere utterance. It is known as the most straightforward sarcasm.

(3) “He’s a fine friend." (Camp, 2011, p. 18)

In (3), the speaker states a proposition about his friend but intends to say the opposite. The speaker does not think that he is a fine friend.

\section{Lexical Sarcasm}

Camp (2011) states that lexical sarcasm "targets expressions which denote the extreme end or a conventionally-associated,normatively-loaded cale". The usage of expressions such as "brilliant" and "genius" allows the sarcastic utterance to give a value at the scale's other end. Lexical sarcasm often 
uses allusive or comparative expressions like "so" or "such a". The allusive expressions help to exaggerate the sarcastic utterance. This class of sarcasm delivers an inverted compositional value for a single expression or phrase within the uttered sentence.

(4) "Because George has turned out to be such a diplomat, we've decided to transfer him to Payroll, where he'll do less damage." (Camp, 2011, p. 14)

In (4), George is being transferred to Payroll because he is not doing well. The speaker expresses this in a normal way which does not invert the whole meaning. However, as the speaker used the term 'diplomat' which is contradictory, thus, making this utterance sarcastic.

\section{Like-prefixed Sarcasm}

Often prefixed with "Like/As if" that commits the speaker to deny the content, in a way that is less strongly. This type of sarcasm is only suitable when combined with declarative sentences.

(5) “Like that's a good idea." (Camp, 2011, p. 14)

(6) "Nice cool day today, huh." (Camp, 2011, p. 31)

For example, in (5), the prefix "like" helps to determine the real meaning, that is, the idea is not good whereas in (6), the utterance is not prefixed with either like/as if. However, it is still uttered sarcastically which means that the weather is hot. In this case, "huh" in the utterance helps to invert the meaning. If it is added with prefix "Like", it will become "Like it is a nice cool day today" with the same meaning.

\section{Illocutionary Sarcasm}

This class of sarcasm is an example of meaning inversion. The speaker expresses the idea which is the opposite of one that is expressed by a sincere utterance. It usually uses illocutionary force rather than assertion and is stated in the contrary to the actual situation.

(7) “Thanks for holding the door." (Camp, 2011, p. 32)

(8) "How old did you say you were?" (Camp, 2011, p. 32)
In (7), the speaker pretends to thank the hearer when in reality, the hearer does not actually hold the door. The speaker makes the comment which he/she thinks appropriate whereas the actual situation is the opposite; the hearer does not hold the door for the speaker. The speaker also expresses the utterance to show that the actions of the hearer is impolite.

In (8), the speaker pretends to question the hearer's age to make him/her aware of having demonstrated immature attitude or behaviors, which he/she would not be supposed to do.

\section{Social Variables}

Defined by Cambridge Dictionary, sarcasm is the usage of remarks that means oppositely of what is said and usually used with the motives to hurt someone's feelings or to criticize something in a humorous way. Culpeper states that sarcasm (also known as mock politeness) is a Face Threatening Act (FTA) which is done by using politeness to show the insincerity (2016). Brown and Levinson state that "any action that impinges to some degree upon a person's face (typically orders, insults, criticisms) is a face-threatening act" (1987).

Generally, people tend to avoid FTAs to save face (being humiliated). The FTA done by the speakers are influenced by three social variables, which are Distance (D), Relative Power (P) and Absolute Ranking (R). However, in this research, the researcher focus on two social variables, which are Social Distance and Relative Power.

Social Distance has binary value of negative and positive distance, whereas Relative Power has trinary value of positive, negative and equal power. From these two social variables are six combinations generated.

Combination A $(-\mathrm{D},+\mathrm{P})$ : the hearer knows the speaker well (-D) and the speaker has higher authority $(+\mathrm{P})$

Combination B (-D, -P): the hearer knows the speaker well (-D) and the speaker has lower authority (-P)

Combination $\mathrm{C}(+\mathrm{D},+\mathrm{P})$ : the hearer does not know the speaker well $(+\mathrm{D})$ and the speaker has higher authority $(+\mathrm{P})$ 
Combination $\mathrm{D}(+\mathrm{D},-\mathrm{P})$ : the hearer does not know the speaker well $(+\mathrm{D})$ and the speaker has lower authority (-P)

Combination $\mathrm{E}(-\mathrm{D},=\mathrm{P})$ : the hearer knows the speaker well (-D) and the speaker has equal authority $(=\mathrm{P})$

Combination $\mathrm{F}(+\mathrm{D},=\mathrm{P})$ : the hearer does not know the speaker well $(+D)$ and the speaker has equal authority $(=\mathrm{P})$

\section{METHODS}

The data source of this research is the American TV Series "Friends" Season One. The TV Series are created by David Crane and Maria Kauffman, and released its first season on NBC on September 22, 1994. Season One consists of 24 episodes and each episode aired for approximately 22 minutes. The series were accessed from a streaming website Netflix. The data are dialogues containing sarcasm.

Firstly, the data were collected from the script available in https://fangj.github.io/friends/. Secondly, for the accuracy the data is double crosschecked with the subtitles of the series and the Subscene.com as well by listening to the dialogues carefully. The coding of the data include the episode number along with the timestamp in which the dialogue appears. Lastly, the context is provided for a better understanding of the dialogue.

Following the data collecting is data classification using Camp's theory of sarcasm. The data analysis applies qualitative method and simple calculation. The qualitative method presents the analysis results in the form of description, and the simple calculation presents the results in tables of the frequency of the sarcasm types and combination of social variables.

\section{RESULTS AND DISCUSSION}

\section{Classes of Sarcasm}

There are a total of 67 sarcastic expressions found in the Season 1 of TV Series "Friends". The analysis of sarcastic expressions using Camp's classess of sarcasm (2011) identifies four classes of sarcasm which are Propositional, Lexical, Like-prefixed and Illocutionary Sarcasm. These classes of sarcasm have to be differentiated by the target of the sarcastic pretense. The table below presents the frequency and distribution of the sarcasm.

Table 1. Frequency and Distribution of Sarcasm

\begin{tabular}{|r|l|r|r|}
\hline No. & \multicolumn{1}{|c|}{ Classes of Sarcasm } & Number & \multicolumn{2}{|c|}{$\begin{array}{c}\text { Frequency } \\
\text { (\%) }\end{array}$} \\
\hline 1. & Propositional Sarcasm & 25 & 37 \\
\hline 2. & Lexical Sarcasm & 10 & 15 \\
\hline 3. & Like-Prefixed Sarcasm & 2 & 3 \\
\hline 4. & Illocutionary Sarcasm & 30 & 45 \\
\hline & Total & 67 & 100 \\
\hline
\end{tabular}

Illocutionary Sarcasm is the most frequently used class of sarcasm uttered by the characters in "Friends". From a total number of 67 sarcastic expressions, Illocutionary Sarcasm is used 30 times (45\%). Followed by Propositional Sarcasm with 25 utterances (37\%) and Lexical Sarcasm produce 10 utterances $(15 \%)$. The least used class of sarcasm is Like-prefixed Sarcasm which is used twice (3\%) throughout Season 1. As the table above shows the characters tend to utter the sarcastic expressions by using illocutionary force and inverting the actual meaning.

\section{Propositional Sarcasm}

Propositional sarcasm is the most straightforward sarcasm that follows the traditional manner of meaning inversion (Camp, 2011). One main feature of Propositional Sarcasm is that it targets a specific proposition which a sincere utterance would have been said by the speaker. A Speaker who employs Propositional Sarcasm utters the sarcastic expressions by implicature and often combines pretense as well as presupposition.

(9) S01E09 |00:13:43,155 $\rightarrow$ 00:13:50,537 | PS \#13 | Combination E \#21

Context: Chandler storms into Monica's apartment to inform everyone about Underdog which flew away from the parade.

Chandler: The most unbelievable thing has

happened. Underdog has just gotten away.

Joey: The balloon? 
Chandler: No, no, the actual cartoon character.

To be able to understand the sarcasm in the example above, the hearer has to have common ground knowledge with the speaker. Common ground is defined as mutual knowledge which includes beliefs and suppositions (Clark, 1996). With the context of Chandler's sarcastic response to Joey's question on the Underdog balloon flying away from the parade, they both equip common ground. In this case, Underdog is a cartoon character originated from America which was around from 1965 to 1985 and often used as the main highlight of the Macy's Thanksgiving Parade. As Joey and Chandler are both American, they share a common ground of knowledge regarding Underdog.

In Chandler's sarcastic response, he evokes an evaluative scale which implies the stupidity of Joey's question. His response of "the actual cartoon character" implies to mock Joey because Joey asks whether it was the balloon that flew away and it does not make sense as a cartoon character, a fictive object, is not able to fly away.

As Chandler and Joey are roommates, they have negative distance (-D) and as both of them are friends, they holds equal power $(=\mathrm{P})$. Therefore, Chandler is able to speak sarcastically in a straightforward manner due to their close relationship.

\section{Lexical Sarcasm}

Lexical Sarcasm supports the semantic view of sarcasm where the speaker uttered a speech act which contains illocutionary force without inverting the actual meaning. A distinctive feature of Lexical Sarcasm is that it inverts the meaning of at least one expression (Camp, 2011). Lexical Sarcasm presents a stronger connection of an evoked scale compared to Propositional Sarcasm. Camp (2011) states that lexical sarcasm targets expressions that consist of the extreme end of a normatively-loaded scale. Such expressions as "brilliant", "inspired", "genius" contribute a value to the scale. The targeted expression in lexical sarcasm can have a positive and negative value.
(10) S01E23 | 00:02:19,973 $\rightarrow$ 00:02:33,360 | LS \#10 | Combination B \#6

Context: At the nursing room, Carol, Susan and Ross meet with Dr.Franzblau, their obstetrician.

Dr.Franzblau: So, I understand you're thinking of having a baby? Well, I see you're nine months pregnant. That's a good start. How you doing with your contractions?

Carol: Oh, I love them. Each one's like a little party in my uterus.

In (10), Carol is seen speaking sarcastically using Lexical Sarcasm. Her utterance contains a normatively loaded scale which is evident in her use of expression "like a". This comparative expressions functions to emphasize on her sarcasm towards the hearer.

Although, Carol and Dr. Franzblau holds a doctor-patient relationship, they have (-D) because they meet frequently for consultations. However, due to the settings of where the conversation takes place, Dr. Franzblau holds a higher power than Carol $(+\mathrm{P})$. In accordance to this, Carol employs Lexical Sarcasm to soften the threat towards Dr. Franzblau's and allow him to understand the utterance as a joke.

\section{Like-Prefixed Sarcasm}

Similar to Propositional Sarcasm, Like-prefixed Sarcasm also targets an entire proposition. However, one distinguished feature is that Like-prefixed Sarcasm is combined with declarative sentences that helps to make the sarcasm felicitous (2011). Another feature of Like-prefixed Sarcasm is that the speaker employs deniability.

(11) S01E04 | 00:19:06,395 $\rightarrow$ 00:19:21,826 | LPS \#2 | Combination E \#50

Context: Monica, Rachel and Phoebe are sitting on the balcony, having fun talking about their lies towards each other.

Rachel: Okay, okay, okay, I got one. The valentine Tommy Rollerson left in your locker was really from me.

Monica: Excuse me? 
Rachel: Oh, hello? Like he was really gonna send you one.

According to Camp (2011), the usage of "Like" in an utterance function to allude or evoke a set of circumstances. It is also mentioned that it has a function of "echoing someone else's utterance or thought" that is contrary to the actual situation. Often, Like-prefixed Sarcasm uses intensifiers that push the targeted content towards the extreme end of an evoked scale. In this case, based on the dialogue which Rachel uttered, she employs the intensifier "really". Camp suggests that "Like" prefixed in an utterance expresses a strong evaluative attitude, like how sarcasm is predicted. From the dialogue above, Rachel does not deny the content of the utterance and also expresses her evaluation of it.

Additionally, the nature of the sarcastic utterance highlights the speaker's evaluation to express scorn or sneering tone to any probability of the content. In this case, Rachel expresses her evaluation by dismissing Monica's question that Monica believed the Valentine gift was for her, when in fact, it was for Rachel from Tommy Anderson, a hot guy in their high school and the fact that Monica was fat makes it impossible that he will give her a gift.

Monica and Rachel are friends since they were children (-D) and as conversation is in a casual situation and context, they hold equal power $(=P)$. Their relationship allows Rachel to speak sarcastically in a comfortable manner because she knows that Monica will not get offended by her utterance. In addition, as Like-Prefixed Sarcasm highlights the evaluative attitude towards Monica which is in a sneering tone, she is able to do it because they share a common ground which is required as to not cause the hearer to misunderstand.

\section{Illocutionary Sarcasm}

Camp (2011) states that Illocutionary Sarcasm does not target a single proposition or element only within the uttered sentence, but the entire illocutionary act. This class of sarcasm targets especially speech acts with illocutionary force and include implicature containing evaluative attitudes, such as pity, admiration or surprise.

In Illocutionary Sarcasm, the speaker commits a certain speech act $S$, which will be appropriate in a situation $X$ which contrast with the actual situation $Y$. Illocutionary Sarcasm functions to highlights the contrast or disparity between situation $X$ to the actual situation $Y$ as the two situations are at the opposite ends of an evoked scale.

$$
\begin{aligned}
& \text { S01E02 | 00:02:05,333 } \rightarrow \text { 00:02:16,218 | IS \#2 | } \\
& \text { Combination C \#1 }
\end{aligned}
$$

Context: At Museum of Prehistoric History, Ross and his co-worker, Marsha are setting up the exhibit which include several mannequins of cave people.

Ross: No, it's good, it is good, it's just that- mmdoesn't she seem a little angry?

Marsha : Well, she has issues.

Ross: Does she?

The dialogue above shows how Illocutionary Sarcasm functions to lower the threat towards the hearer's face. In this dialogue, Ross is pretending to question Marsha's answer. The context of the conversation is the expression of the caveman manequin and henceforth Marsha's answer which gives humanly attributes to a non-living object is deemed as nonsensical. Ross is also expressing his evaluative attitude which is to mock Marsha's but he does it in a form of question.

Marsha is Ross's sub-ordinate and their interactions are only limited when they are at the museum, hence they are not close to each other (+D). Due to their positions at work, Ross, a supervisor, holds a higher authority than Marsha $(+\mathrm{P})$. The sarcasm that is in the form of question uttered by Ross "Does she?" shows that Ross has power over Marsha $(+\mathrm{P})$ as he is able to question her response. Accordingly, Ross uses Illocutionary Sarcasm to make the sarcasm unclear as to not offend her. The utterance "Does she?" shows a contrast of the actual situation, i.e., about a statue that is supposed not to have any real issues. 


\section{CONCLUSION}

The research discusses the sarcastic expressions found in Season One of American TV Series Friends (1994) and additionally, it investigates the influence of social variables in the delivery of those expressions. Based on the analysis of 67 expressions uttered by the characters in the series, the most frequently used class of sarcasm is Illocutionary Sarcasm (45\%), followed by Propositional Sarcasm (37\%), Lexical Sarcasm (15\%) and lastly, LikePrefixed Sarcasm (3\%). It can be concluded that the tendency of using Illocutionary Sarcasm is frequent and the speakers often utters the opposite of what a sincere utterance would have meant. Moreover, the speakers employ illocutionary force which will be appropriate to the opposite situation.

As sarcasm is considered as Face Threatening Act (FTA), the research also investigate the influence of social variables on the delivery of the sarcastic expressions. The two social variables that are taken as factors for analysis are Social Distance (D) and Power (P). Six combinations are generated and the findings shows that sarcasm is often delivered in the situation of Combination E (75\%). Combination $\mathrm{E}$ which has the value of negative social distance and equal power shows that the characters deliver their sarcastic expressions when they do not have to be polite, i.e., in a social atmosphere of close relationships among the interlocutors, such as friends. This can be seen by the usage of Propositional Sarcasm and Illocutionary Sarcasm which are frequently used in this combination. These two classes of sarcasm are the most straightforward sarcasm, but the characters are able to comfortably deliver their sarcastic expressions to the hearer.

In contrast, the combinations with value of positive power can vary according to the settings of the conversation. For several cases, although the interlocutors are close, the context of the conversation determine who holds a higher power. When the speaker holds a higher power than the hearer, more direct classes of sarcasm are often used. Combinations A and C which have values of positive power, affecting the usage of Propositional Sarcasm and Illocutionary Sarcasm with 1 (1\%) and 3 occurrences (4\%) respectively.
The findings of this research support the study by Sandy (2012) which focuses on the negative connotations in sarcastic expressions in American sitcom. According to the findings, the majority of the sarcastic expressions uttered by the characters often have negative intentions and hidden meaning such as to criticize or mock the hearer. A clear context is required along with common ground to understand the sarcasm

However, as this research focuses only on the sarcastic expressions found in one season of the TV series, future studies are needed to analyze sarcastic expressions in more episodes or seasons in order to gain detailed results on sarcasm. Further research regarding the functions of the sarcastic expressions can be carried out to identify the intention underlying the use of sarcasm. Apart from that, the study on sarcastic expressions in more seasons of the TV series will provide varied settings and contexts which allow a more profound understanding on the influence of social variables in those expressions.

\section{REFERENCES}

Austin, L. (1962). How to do things with words. Oxford: Clarendon Press.

Bachtiar, E. (2018). Sarcastic expressions in the movies Fantastic Four (2004) and Fantastic Four: Rise of The Silver Surfer (2007). (Unpublished undergraduate Thesis), Universitas Gadjah Mada, Yogyakarta, Indonesia.

Brown, P. \& Levinson, S. (1987). Politeness: Some universals in language usage. Cambridge: Cambridge University Press.

Camp, E. (2011). Sarcasm, pretense and the semantics/pragmatics distinction. Nous, 46 (4), 1-48. Doi: https://doi.org/10.1111/j.14680068.2010.00822.x.

Caucci, G. \& Kreuz, R. (2012). Social and paralinguistic cues to sarcasm. International Journal of Humor Research, 25(1), 1-22. Doi: 10.1515/humor-2012-0001

Clark, H. (1996). Common ground. Using Language. Cambridge: Cambridge University Press. 
Colston, H. (2017). Irony and sarcasm. In S. Attardo (ed.), The Routledge Handbook of Language and Humor (pp. 234-249). New York: Routledge.

Context. (n.d). in Merriam-Webster online dictionary. Retrieved from https://www.merriamwebster.com/dictionary/context.

Crane, D. \& Kauffman, M. (1994). Friends. Warner Bros. Television.

Culpeper, J. (1996). Towards an anatomy of impoliteness. Journal of Pragmatics, 25, 349367. Elsevier.

Culpeper, J. (2016). Impoliteness strategies. Interdisciplinary Studies in Pragmatics, Culture and Society, Perspectives in Pragmatics, Philosophy \& Psychology, 4, 421445. Doi: 10.1007/978-3-319-12616-6

Cutting, J. (2002). Pragmatics and discourse: $A$ resource book for students. London: Routledge.

Fangj.github.io. (n.d). Friends transcripts. Retrieved from https://fangj.github.io/friends/.

Haiman, J. (1998). Talk is cheap: Sarcasm, alienation $\&$ the evolution of language. Oxford: Oxford University Press

Jayanti, C. (2017). An analysis of types and degree and translation quality of sarcasm expressions in the movie The Godfather (1972) and The Godfather Part II. (Unpublished undergraduate Thesis), Universitas Negri Sebelas Maret, Surakarta, Indonesia.

Kang, H. (2012). The interpretation of linguistic sarcasm. The Sociolinguistic Society of Korea, 21(2), 29-46. Doi: https://doi.org/10.14353/ sjk.2013.21.2.29.
Liberman, M. (2004). Speaking sarcastically?. Language Log. Retrieved from http://itre.cis.upenn.edu/ myl/languagelog/arc hives/001207.html.

McDonald, S. (1999). Exploring the process of inference generation in sarcasm: A review of normal and clinical studies. Brain and Language, 68(3), 486-506.

Netflix. (n.d). Friends. Retrieved from https://www.netflix.com/id-en/title/70153404.

Peccei, J. (1999). Pragmatics language workbooks. Taylor \& Francis Routledge.

Prabowo, M. (2013). Sarcastic expressions in the movie The Guard. (Unpublished undergraduate Thesis), Universitas Gadjah Mada, Yogyakarta, Indonesia.

Sandy, S. (2012). A study of mock politeness in conversation: Sarcasm usage in American sitcoms. (Unpublished undergraduate Thesis), University of Wolverhampton, USA.

Sarcasm. (n.d). In Cambridge online dictionary. Retrieved from https://dictionary.cambridge.org/dictionary/e nglish/sarcasm.

Subscene. (2020). Friends - First season. Accessed on 22 January 2020. Retrieved from https://subscene.com/subtitles/friends--firstseason/english/676023.

Toplak, M. \& Katz, A. (2000). On the uses of sarcastic irony. Journal of Pragmatics, 32(10), 1467-1488. Doi: http://dx.doi.org/10.1016/S03782166(99)00101-0.

Yule, G. (1996). Pragmatics. Oxford: Oxford University Press. 